\title{
DECONSTRUCTING THE ESSENTIAL FATHER
}

\author{
Louise B. Silverstein, Ph.D.and Carl F. Auerbach, Ph.D. \\ Yeshiva University \\ from the AMERICAN PSYCHOLOGIST, Volume 54, Number 6 (June 1999)
}

\begin{abstract}
Neoconservative social scientists have claimed that fathers are essential to positive child development, and that responsible fathering is most likely to occur within the context of heterosexual marriage. This perspective is generating a range of governmental initiatives designed to provide social support preferences to fathers over mothers; and to heterosexual married couples, rather than to alternative family forms.

The current article proposes that the neoconservative position is an incorrect or oversimplified interpretation of empirical research. Using a wide range of cross-species, cross-cultural, and social science research, the authors argue that neither mothers nor fathers are essential to child development, and that responsible fathering can occur within a variety of family structures. The article concludes with alternative recommendations for encouraging responsible fathering that do not discriminate against mothers and diverse family forms.
\end{abstract}

In the past two decades there has been an explosion of research on fathers (see Booth \& Crouter, 1998; Lamb, 1997; and Phares, 1996 for recent reviews). There is now a broad consensus that fathers are important contributors to both normal and abnormal child outcomes. Infants and toddlers can be as attached to fathers as they are to mothers. In addition, even when fathers are not physically present, they may play an important role in their children's psychological lives. Other important issues about fathers and families remain controversial. For example, scholars continue to debate the extent to which paternal involvement has increased over the past 20 years (Pleck, 1997). Similarly, we are only beginning to study the ways that fathering identities vary across subcultures (Auerbach, Silverstein, \& Zizi, 1997; Bowman \& Forman, 1998; Roopnarine, Snell-White, \& Riegraf, 1993). Nor do we understand clearly the effects of divorce on fathers and their children (Hetherington, Bridges, \& Insabella, 1998).

Overall, this explosion of research on fathering has increased the complexity of scholarly thinking about parenting and child development. However, one group of social scientists (e. g. Biller \& Kimpton, 1997; Blankenhorn, 1995; Popenoe, 1996) has emerged that is offering a more simplistic view of the role of fathers in families. These neoconservative social scientists have replaced the earlier "essentializing" of mothers (Bowlby, 1951) with a claim about the essential importance of fathers. These authors have proposed that the roots of a wide range of social problems (i. e. child poverty, urban decay, societal violence, teenage pregnancy, and poor school performance) can be traced to the absence of fathers in the lives of their children. Biller 
\& Kimpton (1997, p. 147) have even used the term "paternal deprivation" in a manner parallel to Bowlby's concept of maternal deprivation. In our view, the essentialist framework represents a dramatic oversimplification of the complex relations between father presence and social problems.

We characterize this perspective as "essentialist" because it assumes that the biologically different reproductive functions of men and women automatically construct essential differences in parenting behaviors. The essentialist perspective defines mothering and fathering as distinct social roles that are not interchangeable. Marriage is seen as the social institution within which responsible fathering and positive child adjustment are most likely to occur. Fathers are understood as having a unique and essential role to play in child development, especially for boys who need a male role model in order to establish a masculine gender identity (See Table 1 for a definition of the essentialist perspective).

Our research experience has led us to conceptualize fathering in a way that is very different from the neoconservative perspective. Over the past six years, we have studied the fathering identities of men who are actively involved with their children (Auerbach et al., 1997; Auerbach \& Silverstein, 1997; Silverstein, 1996; Silverstein \& Phares, 1996; Silverstein \& Quartironi, 1996;

\section{Table 1.}

\section{The Essentialist Paradigm.}

\section{Biological Sex Differences Construct Gender Differences in Parenting.}

The biological experiences of pregnancy and lactation generate a strong, instinctual drive in women to nurture. In the absence of these experiences, men do not have an instinctual drive to nurture infants and children.

\section{The Civilizing Effects of Marriage.}

a. Because a man's contribution to reproduction is limited to the moment of conception, active and consistent parenting on the part of men is universally difficult to achieve.

b. The best way to insure that men will consistently provide for and nurture young children is to provide a social structure in which men can be assured of the paternity, i.e. the traditional nuclear family. Without the social institution of marriage, men are likely to impregnate as many women as possible, without behaving responsibly to their offspring.

\section{The importance of a male role model.}

If men can be induced to caretake young children, their unique, masculine contribution significantly improves developmental outcomes for children. This is especially true for boys who need a male role model in order to achieve a psychologically healthy masculine gender identity. 


\section{AMERICAN PSYCHOLOGIST, VOLUME 54, NUMBER 6}

Silverstein, Auerbach, Grieco, Dunkel, in press). To date, approximately 200 men from 10 different subcultures within U. S. society have participated in this qualitative research. Our research participants include: Haitian Christian fathers; Promise Keeper fathers; gay fathers; Latino fathers; White, non-gay divorced, fathers; Modern Orthodox Jewish fathers; Greek grandfathers.

In contrast to the neoconservative perspective, our data on gay fathering couples have convinced us that neither a mother nor a father is essential. Similarly, our research with divorced, never-married, and remarried fathers has taught us that a wide variety of family structures can support positive child outcomes. We have concluded that children need at least one responsible, caretaking adult who has a positive emotional connection to them, and with whom they have a consistent relationship. Because of the emotional and practical stress involved in childrearing, a family structure that includes more than one such adult is more likely to contribute to positive child outcomes. Neither the sex of the adult(s), nor the biological relationship to the child has emerged as a significant variable in predicting positive development. One, none, or both of those adults could be a father [or mother]. We have found that the stability of the emotional connection and the predictability of the caretaking relationship are the significant variables that predict positive child adjustment.

We agree with the neoconservative perspective that it is preferable for responsible fathers [and mothers] to be actively involved with their children. We share the concern that many men in U. S. society do not have a feeling of emotional connection or a sense of responsibility toward their children. However, we do not believe that the data support the conclusion that fathers are essential to child well-being, and that heterosexual marriage is the only social context in which responsible fathering is most likely to occur.

Many social scientists believe that it is possible to draw a sharp distinction between scientific fact and political values. From our perspective, science is always structured by values, both in the research questions that are generated, and in the interpretation of data. For example, if one considers the heterosexual nuclear family to be the optimal family structure for child development, then one is likely to design research that looks for negative consequences associated with growing up in a gay or lesbian parented family. If, in contrast, one assumes that gay and lesbian parents can create a positive family context, then one is likely to initiate research that investigates the strengths of children raised in these families.

The essentialist theoretical framework has already generated a series of social policy initiatives. For example, a 1998 Congressional seminar that recommended a series of revisions to the tax code that would: reward couples who marry; and end taxes altogether for married couples with three or more children (Wetzstein, 1998). Other federal legislation has emerged with a similar emphasis on the advantages of marriage. The 1996 welfare reform law begins by stating, "Marriage is the foundation of a successful society" (Welfare Reform Act, 1996, p.110). Similarly, a housing project in Hartford, Connecticut now provides economic supports to married couples, and special opportunities for job training to men (but not to women) who live with their families (LaRossa, 1997). In 1997, Louisiana passed a Covenant Marriage Act (1997) that declared marriage a lifelong relationship, and stipulated more stringent requirements for separation and divorce. 


\section{AMERICAN PSYCHOLOGIST, VOLUME 54, NUMBER 6}

The social policy emerging out of the neoconservative framework is of grave concern to us because it discriminates against cohabiting couples, single mothers, and gay and lesbian parents. The purpose of the current article is to present a body of empirical data that illustrates the inaccuracy of the neoconservative argument. Throughout our discussion, we focus on the work of Blankenhorn (1995) and Popenoe (1996) because they have been most influential in structuring both public debate and social policy (Haygood, 1997; Samuelson, 1996).

Specific aspects of the neoconservative paradigm have been critiqued elsewhere. For example, McLoyd (1998) has pointed out that families without fathers are likely to be poor; and it is the negative effects of poverty, rather than the absence of a father, that lead to negative developmental outcomes. Similarly, Hetherington, et al. (1998) have made the point that divorce does not always have negative consequences for children. However, the neoconservative argument as a whole has not been deconstructed. Thus, it tends to be absorbed in a monolithic fashion, buttressed by unconscious gender ideology and traditional cultural values. Therefore, we think that a systematic counterargument is necessary. We will cite research indicating that parenting roles are interchangeable; that neither mothers nor fathers are unique or essential; and that the significant variables in predicting father involvement are economic, rather than marital. We will also offer an alternative framework for encouraging responsible fathering.

We acknowledge that our reading of the scientific literature supports our political agenda. Our goal is to generate public policy initiatives that support men in their fathering role, without discriminating against women and same-sex couples. We are also interested in encouraging public policy that supports the legitimacy of diverse family structures, rather than policy that privileges the two-parent, heterosexual, married family.

We also realize that some of the research we cite to support our perspective will turn out to be incorrect. Haraway (1989) pointed out that, as research paradigms evolve to reflect diverse gender, ethnic, class, and cultural perspectives, much of the established body of "scientific fact" has turned out to be science fiction. Fishhoff (1990) identified two options for psychologists in the public arena: helping the public define their best interests, or manipulating the public to serve the interests of policymakers. Thus, despite the fact that new data will inevitably prove some aspects of our argument wrong, we hope that by stimulating scholarly debate, we will contribute to the process by which the public more accurately defines its best interests.

We begin by presenting cross-species and cross-cultural data that contradict the claim that parenting behaviors are constructed by biological differences. We will argue that parenting involves a series of caregiving functions that have developed as adaptive strategies to specific bioecological contexts. These caregiving functions can be performed by parenting figures of either sex, whether or not they are biologically related to the child.

We then review the research on marriage and divorce. This body of data suggests that the poor psychological adjustment observed in some children in divorcing families is caused by the disruption of the child's entire life circumstances, rather than simply the dissolution of the marriage or the absence of a father. We present data illustrating that emotionally connected, actively nurturing, and responsible fathering can occur within a variety of family structures. 


\section{AMERICAN PSYCHOLOGIST, VOLUME 54, NUMBER 6}

Finally, we examine why the neoconservative perspective has been so widely accepted within popular culture. We speculate that the appeal of neoconservative ideology is related to two social trends: a genuine concern about children; and a backlash against the gay rights and feminist movements. We then offer social policy recommendations that support men in their fathering role, without discriminating against women and same-sex couples.

\section{The Essentialist Position}

\section{Biological Sex Differences Construct Gender Differences in Parenting}

One of the cornerstones of the essentialist position is that biological differences in reproduction construct gender differences in parenting behaviors. This theoretical framework proposes that the biological experiences of pregnancy and lactation generate a strong, instinctual drive in women to nurture. This perspective assumes that men do not have an instinctual drive to nurture infants and children.

The neoconservative perspective relies heavily on evolutionary psychology to support this argument. Evolutionary psychologists cite Trivers' (1972) sexual conflict of interest hypothesis to explain sex differences in mating strategies. Trivers' hypothesis states that, all other things being equal, male mammals will maximize their evolutionary fitness by impregnating as many females as possible, while investing very little in the rearing of any individual offspring. Female mammals, in contrast, invest a great deal of physiological energy in pregnancy and lactation, and thus are motivated to invest a corresponding amount of time and energy in parenting.

Trivers' hypothesis accurately predicts behavior in many mammalian species. However, Smuts \& Gubernick (1992) have shown this hypothesis to be inaccurate in predicting male involvement with infants among nonhuman primates. Unfortunately, Smuts' and Gubernick's critique of the relevance of Trivers' hypothesis for primate behavior has not been integrated into evolutionary psychological theory.

Evolutionary psychology has recently gained prominence within psychology and other social sciences (e. g. Archer, 1996; Buss, 1995). Because the formal academic training of most social scientists does not include cross-species research and evolutionary theory, many social scientists have accepted the evolutionary psychologists' use of the Trivers hypothesis in relation to primate behavior. However, many scholars within the natural science community have been critical of evolutionary psychology (see for example the 20 plus negative commentaries on Thornhill \& Thornhill, 1992; or Gould's, 1997 critique of evolutionary psychology).

Blankenhorn (1995) and Popenoe (1996), like many social scientists, have incorrectly assumed that Trivers' theory is true of all primates, and universally applicable across many different ecological contexts. However, all other things have generally not been equal over the course of evolutionary history. As bioecological contexts change, so do fathering behaviors, especially among primate males.

Marmosets are an extreme example of primates who live in a bioecological context that requires males to become primary caretakers (Smuts \& Gubernick, 1992). Because marmosets always 


\section{AMERICAN PSYCHOLOGIST, VOLUME 54, NUMBER 6}

have twins, female marmosets must nurse two infants simultaneously. This generates nutritional pressure for the mother to spend all of her time and energy feeding herself. Therefore the father most commonly performs all parenting behaviors. Thus, these animals do not conform to Trivers' hypothesis about the universality of non-nurturing primate males. Marmoset males behave like "full-time mothers."

Marmosets illustrate how, within a particular bioecological context, optimal child outcomes can be achieved with fathers as primary caretakers and limited parenting involvement by mothers. Human examples of this proposition include: single fathers (Greif \& DeMaris, 1990); a two-parent family in which the father is the primary caretaker (Pruett, 1989); or gay father-headed families (Patterson \& Chan, 1997).

Another cornerstone of the essentialist position is that the traditional division of labor characteristic of Western, industrialized societies has been true throughout human evolutionary history. Popenoe (1996. P. 167) stated that our hominid ancestors "had a strong division of labor in which males did most of the hunting and females did most of the gathering." Zihlman (1997), in contrast, has pointed out that for most of our evolutionary history, human societies were nomadic. This bioecological context required both men and women to travel long distances, hunt, gather food, and care for older children and other members of their community. Similarly, in contemporary foraging and horticultural societies, women perform the same range of tasks as men do, and add infant care to their other responsibilities. Cross-cultural research illustrates that women are capable of traveling long distances, carrying heavy loads, and participating in hunting. Thus, the assertion that a rigid sexual division of labor existed over most of our evolutionary history is not supported, either by what is known about human society in prehistory, or by contemporary preagricultural cultures.

The neoconservative perspective has also assumed that providing has been a universal male role. Yet Nsamenang (1992) pointed out that in many West African rural cultures, tradition places the sole responsibility for providing food on mothers. Similarly, in hunting-gathering cultures, women typically provide $60 \%$ of a family's nutritional requirements (Zihlman, 1997). Thus, in most preindustrial cultures fathers have never been sole providers, and in some cultures they do not participate at all in the provider role.

The neoconservative perspective has also claimed that mothers are more "natural" caregivers than fathers. Yet, more than a decade ago, Lamb (1987) reported that research on mothers and fathers during the newborn period yielded no differences in parenting behaviors. Neither mothers nor fathers were "natural" parents. Because mothers tended to spend so much more time with their infants, they became much more familiar with their biological rhythms, visual and behavioral cues, etc. Therefore, when observations were repeated after a year, mothers appeared as much more competent caregivers than fathers. Many subsequent studies have shown that when fathers assume the primary caretaking role, they are as competent and as "sensitive" as mothers (Lamb, 1997).

In summary, the neoconservative position is simply wrong about the biological basis of observed differences in parenting behaviors. Cross-species and cross-cultural data indicate that fathering can vary from a high level of involvement, to a total lack of involvement. Given these wide 


\section{AMERICAN PSYCHOLOGIST, VOLUME 54, NUMBER 6}

variations in paternal behaviors, it is more accurate to conclude that: both men and women have the same biological potential for nurturing; and that the sexual division of labor in any culture is defined by the requirements of that culture's specific bioecological context.

\section{"Marriage Matters"}

The neoconservative perspective has argued that, without a biological basis for nurturing in men, the best way to insure that men will behave responsibly toward their offspring is to provide a social structure in which men can be assured of paternity, i. e. the traditional nuclear family.

\section{Nonhuman primate behavior}

This point of view is based on a corollary of Trivers' (1972) sexual conflict of interest hypothesis, the paternity hypothesis. Trivers reasoned that without paternity certainty, males would not risk investing time and energy in another male's offspring, thereby decreasing their own evolutionary fitness. However, Smuts and Gubernick (1992) have demonstrated that Trivers' paternity hypothesis is not generally predictive of fathering behavior among nonhuman primates. If paternity certainty were the most significant variable, then males should show greater paternal involvement in species where several females live with only one breeding male. In species where several males and several females live together (and therefore multiple mating opportunities make paternity uncertain), males should have lower paternal involvement.

The paternity hypothesis does correctly predict male care of infants in most monogamous species. In most monogamous mating pairs, male care is high. However, the paternity hypothesis does not accurately predict male care in other primate social groupings. With the exception of mountain gorillas, males in one-male groups (where paternity is certain) show less paternal involvement than males in multimale groups (where paternity is uncertain).

Smuts and Gubernick found that the amount of time and energy males invest in nurturing and protecting infants varies depending on the mutual benefits which males and females have to offer each other within a particular bioecological context. These authors offered an alternative hypothesis, the "reciprocity hypothesis," to account for variations in male care of infants. The reciprocity hypothesis predicts that male care of infants will be low when either males or females have few benefits to exchange. The probability of high male care of infants increases when females have substantial benefits to offer males (e. g. when females can offer to mate more frequently with specific males; or provide males with political alliances that enhance their status within the male dominance hierarchy).

Smuts and Gubernick found that male care of infants is lower in one-male groups because this system of reciprocal benefits does not exist. Each female has no alternative except to mate with the single male, whether or not he cares for her infants. Because she has no other mating possibilities, she cannot offer preferential mating opportunities in exchange for infant care. Similarly, in a one-male group, the breeding male does not have to compete for a place within a male dominance hierarchy. He is the only male in the group. Therefore, females cannot offer political assistance to enhance his dominance ranking. Because females lack benefits to offer 


\section{AMERICAN PSYCHOLOGIST, VOLUME 54, NUMBER 6}

males in exchange for infant care, male involvement, in contrast to what would be predicted by the paternity hypothesis, is low in one-male groups.

Overall, a very large body of animal research points to the importance of an array of variables, which we refer to as bioecological context, in determining parenting behaviors. Low levels of infant care do not characterize all primate males. Nor is biological paternity the most significant variable in increasing the probability of high male involvement. Other feminist anthropologists and sociobiologists have similarly deconstructed Trivers' theory (e. g. Gowaty, 1997; Hrdy, 1997).

In contrast to Trivers' emphasis on universal sex differences and the relative fixity of behaviors, these feminist researchers have pointed to the overlap of behaviors between the sexes, and the relative flexibility of complex human behaviors. Unfortunately, this feminist scholarship has not been integrated into most social science literature.

\section{Human primate behavior}

Smuts and Gubernick have made a strong case for the power of the reciprocity hypothesis to predict male involvement among nonhuman primates. However, does their hypothesis predict human primate behavior? We will argue that the reciprocity hypothesis does predict male involvement among human primates.

In cultures where women have significant resources to offer men in exchange for childcare, paternal involvement should be higher than in cultures where women have fewer resources. In line with this prediction, paternal involvement in the U. S., Sweden, and Australia is higher than in more traditional cultures, such as Italy and Spain, where women's workforce participation is less widespread (Blossfeld, 1995). Similarly, Haas (1993) reported that a survey of more than 300 Swedish families indicated that fathers participated more in child care if their partner made as much or more money than they did.

Erikson and Gecas (1991) have provided examples of how paternal involvement varies based on the benefits men have to exchange. These authors pointed out that the least amount of father involvement in U. S. society has been observed in two groups of fathers: poor, unmarried teenage fathers; and upper-class fathers in traditional nuclear families. Teen dads in U. S. society are often undereducated and underemployed. Therefore, they cannot make a meaningful contribution to the economic security of their children. Poor teen fathers do not have meaningful benefits to offer their child's mother. As the reciprocity hypothesis would predict, these fathers are often minimally involved in the lives of their children.

In upper-class families, in contrast, it is most often the wives who have few benefits to exchange. The family's high income is the result of the husband's earning capacity. The wife's additional economic contribution is rarely meaningful to the family's economic security. Most of the wives do not participate in paid employment. Thus, the upper class wives have few benefits to offer in exchange for direct paternal involvement. Within this context, the fathers in these families use their income to pay for other-than-mother childcare, but do little active caregiving themselves. 


\section{AMERICAN PSYCHOLOGIST, VOLUME 54, NUMBER 6}

The fathers with the highest level of active childcare involvement are in dual-shift, working-class families. Pleck (1993) has estimated that fathers in this family context are responsible for, on average, $30 \%$ of childcare. Working class, dual shift families are the context in which mothers and fathers are most evenly matched in terms of the resources they have to exchange. Both parents' incomes are significant to family stability. Because they work opposite shifts, involvement in childcare by the at-home parent is necessary for child well-being. From the perspective of the reciprocity hypothesis, the parity of resources between husband and wife within this family structure generated the high level of paternal involvement.

Stier and Tienda (1993) have provided other data that support the link between father involvement and economic benefits. Using interviews from more than 800 resident and non-resident fathers living in poor neighborhoods in Chicago, these authors examined the relations between paternal support and several background variables. The researchers found that the only significant predictors of which fathers would pay child support were those that reflected the father's economic status. Fathers who were currently employed were three times more likely to support their nonresident children compared to fathers who were not working.

In summary, these data on human parenting behaviors conform to the predictions of the reciprocity hypothesis. In social contexts where either the father or mother has few benefits to exchange, paternal involvement is low. When both fathers and mothers have benefits that contribute to family wellbeing, paternal involvement is relatively high.

Thus, improving employment opportunities for women, as well as men, is crucial to increasing father involvement. These findings suggest that in our current cultural context, it is economics, not marriage, that "matters."

\section{The Civilizing Effects of Marriage}

The essentialist position has also proposed that marriage has a "civilizing"' effect on men. Popenoe, reflecting this point of view, has stated that "...all successful societies have imposed social sanctions on men...the most important of these is the institution of marriage" (p. 164). Similarly, Blankenhorn (1995, p.223) declared that "marriage constitutes an irreplaceable life support system for effective fatherhood."

Blankenhorn further asserted that marriage protects women and children from domestic violence (1995, p. 34). He reported that, as the percentage of men living within the confines of marriage has declined over the past two decades, domestic violence has increased. However, a recent report on intimate violence published by the U. S. Department of Justice (1998) indicated that, as marriage has declined over the past two decades, so has intimate violence. This report stated that murders of women by their intimate partners decreased $40 \%$, from 3,000 in 1976, to 1800 in 1996. Similarly, non-lethal violence (sexual assault, robbery, aggravated and simple assault), declined from 1.1 million reported incidents in 1993, to 840,000 in 1996 (U. S. Department of Justice, 1998).

Blankenhorn and Popenoe have also argued for the protective effect of biological fatherhood within the context of marriage. Citing a study by Daly \& Wilson (1985), Blankenhorn claimed 


\section{AMERICAN PSYCHOLOGIST, VOLUME 54, NUMBER 6}

that children are more frequently abused by stepfathers than by biological fathers. However, Sternberg (1997) pointed out that Daly and Wilson specified only that the more frequently abused children lived in households with stepfathers. They could not specify whether the perpetrator of the abuse was the stepfather, the biological mother, or another adult in the household. Malkin and Lamb (1994), in an attempt to correct for this design flaw, included information about the perpetrator's gender and relationship to the child. They found that biological caretakers, in both stepfamilies and biological families, were more likely to engage in serious physical abuse than stepparents. Nonbiological caretakers, in contrast, committed minor abuse.

These findings are confirmed by the Third National Incidence Study of Child Abuse and Neglect (Sedlak \& Broadhurst, 1996). This study reported that the majority (78\%) of children who suffered maltreatment, both neglect and abuse, were maltreated by a birth parent. Parent substitutes (foster, adoptive, step) were responsible for the abuse in only $14 \%$ of reported cases. In terms of sexual abuse, $46 \%$ of children were sexually abused by a stranger. Birth parents were about as likely to be sexually abusive (29\%) as were parent-substitutes (25\%). These statistics do not support the neoconservative contention that stepfathers or mother's boyfriends abuse children more frequently than biological fathers (and mothers).

In a comprehensive article reviewing the nature, causes, and consequences of abuse, Emery and Laumann-Billings (1998) have identified multiple variables that lead to abuse. These include: personality of the perpetrator, such as low self-esteem or poor impulse control; characteristics of the immediate family context, such as job loss; and qualities of the broader ecological context, such as poverty or high levels of violence in the community. Stepchildren, unplanned children, and children in large families are all at greater risk for abuse. Thus, high levels of child abuse are associated with a broad array of biopsychosocial variables. In summary, we do not find any empirical support that marriage enhances fathering, or that marriage "civilizes" men and protects children.

\section{Fathers Make a Unique and Essential Contribution to Child Development}

The neoconservative perspective has proposed that, if men can be induced to caretake young children, their unique, masculine contribution significantly improves the developmental outcomes for children. From the essentialist perspective, "fatherhood privileges children...Conversely, the primary consequences of fatherlessness are rising male violence and declining child well-being and the underlying source of our most important social problems..." (Blankenhorn, 1995, p. 25-26).

These claims represent an oversimplification of the data. On average, children from divorced families have been shown to be at greater risk for a range of problems than are children from nondivorced families. However, it is also true that $75 \%$ of children from divorced families exhibit no negative effects (see Hetherington, et al., 1998 for a review). Furthermore, the size of the negative effect of divorce is considerably reduced when the adjustment of children preceding divorce is controlled. For many of these children, the problems attributed to divorce were actually present prior to the divorce. In addition, divorce does not affect all children negatively. Amato, Loomis, \& Booth (1995) reported that, although children from low-conflict marriages 


\section{AMERICAN PSYCHOLOGIST, VOLUME 54, NUMBER 6}

were stressed by divorce, the adjustment of children in high-conflict marriages actually improved after divorce. Overall, the research suggests that divorce does not irretrievably harm the majority of children.

Hetherington, et al. (1998) have pointed out that divorce is not a single event, but rather a cycle of negative events. The cycle begins with marital conflict, followed by dissolution of the current family structure, and culminates with the formation of separate households. In the majority of families, at least one parent remarries, forming a new, blended stepfamily. In addition, divorce occurs more frequently in second marriages, reinitiating the disruptive cycle of loss and conflict. This cycle entails economic stress, disrupted attachments, and often separation from the family home and neighborhood.

In his deconstruction of Bowlby's maternal deprivation hypothesis, Rutter (1974) illustrated that the negative developmental outcomes observed in institutionalized infants were caused by the disruption of the child's entire life circumstances, rather than simply separation from mother. Likewise, it seems more probable that the link between marital transitions and negative developmental outcomes is due to the disruption in the entire life circumstances of children, rather than simply to the absence of a father.

Blankenhorn's and Popenoe's reliance on the father-absence research paradigm is surprising, since the limitations of this approach have been documented by many researchers over the past two decades (see Phares, 1996 for a review). Father absence covaries with other relevant family characteristics, i. e. the lack of a male income; the absence of a second adult; and the lack of support from a second extended family system. McLoyd (1998) has pointed out that, because single-mother families are over-represented among poor families, it is difficult to differentiate the effects of father absence from the effects of low income.

Another major limitation to this paradigm is that father absence is not a monolithic variable. Qualitative research has shown that relationships between "absent" fathers and their children can vary widely. Weil (1996) studied 22 divorced fathers who were recruited from a self-help fathers' rights group. These middle-class, suburban, mostly White fathers used a variety of settings, e. g. school, day care, extended-family events, to increase their interaction with their children above the limited contact specified in their visitation arrangements. In another study, Way and Stauber (1996) interviewed 45 urban adolescent girls about their relationships with their fathers. Of the 26 girls who did not live with their fathers, 7 reported weekly contact with them; 10 reported occasional contact; while only 9 reported almost no contact. Thus, father involvement exists on a continuum, whether or not fathers live with their children. Fathers can be "absent" even when they reside with their children, and "present" despite nonresident status.

The essentialist position also fails to acknowledge the potential costs of father presence. Engle \& Breaux (1998) have shown that some fathers' consumption of family resources in terms of gambling, purchasing alcohol, cigarettes, or other nonessential commodities, actually increased women's workload and stress level. 


\section{AMERICAN PSYCHOLOGIST, VOLUME 54, NUMBER 6}

\section{The importance of a male role model}

Another aspect of the neoconservative perspective is the argument that "key parental tasks belong essentially and primarily to fathers" (Blankenhorn, 1995, p.67). Fathers are seen as essential role models for boys, relationship models for girls, and "protectors" of their families (Popenoe, 1996, p. 77). However, there is a considerable body of empirical evidence that contradicts these claims.

The essentialist perspective assumes that boys need a heterosexual male parent in order to establish a masculine gender identity. Pleck (1995) has demonstrated that empirical research does not support this assumption. Similarly, a significant amount of research on the children of lesbian and gay parents has shown that children raised by lesbian mothers (and gay fathers) are as likely as children raised in a heterosexual, two-parent family to achieve a heterosexual gender orientation (Patterson, 1995; Patterson and Chan, 1997). Other aspects of personal development and social relationships were also found to be within the normal range for children raised in lesbian and gay families.

However, persistent, although inconsistent, findings suggest that the negative impact of divorce is more significant for boys than girls. After reviewing the divorce and remarriage research, Hetherington et al. (1998, p. 178) concluded that "the presence of a father may have positive effects on the well-being of boys." These authors also pointed out that the research is not clear as to how father presence acts as a protective factor for boys. Lytton and Romney (1991) in a meta-analysis of 172 studies found very few significant differences in the ways that mothers and fathers treated girls and boys. Similarly, Lamb (1997) concluded that "very little about the gender of the parent seems to be distinctly important" (p. 10). Thus, the relation between father presence and better developmental outcomes for boys remains correlational, not causal.

We speculate that the larger cultural context of male dominance and negative attitudes toward women may interfere with the ability of many single mothers to establish an authoritative parenting style with male children. Within patriarchal culture, boys know that when they become adult men, they will be dominant to every woman, including their mother. This cultural context, unmediated by a male presence, may undermine a single mother's authority with her sons. Qualitative research is needed to explore the subjective experiences of boys in single mother, single father, and two-parent nuclear families in order to understand these persistent, but unclear findings.

Taken as a whole, the empirical research does not support the idea that fathers make a unique and essential contribution to child development. $>$ From our perspective, it is not the decline of marriage that is discouraging responsible fathering. Rather, various social conditions inhibit involved parenting by unmarried and divorced men. For example, unmarried teen fathers typically have low levels of education and job training. Thus, they lack the ability to contribute significantly to the economic security of their offspring. Similarly, many divorced fathers cannot sustain a positive emotional connection to their children after the legal system redefines their role from parenting to visitation. 


\section{AMERICAN PSYCHOLOGIST, VOLUME 54, NUMBER 6}

Social policy is needed that removes the impediments to paternal involvement for never-married and divorced fathers. Rather than privileging the institution of heterosexual marriage at the expense of other family structures, it is essential to strengthen the father-child bond within all family contexts, especially nonmarital contexts.

\section{Change and the Change-back Reaction}

If the essentialist paradigm is not supported by empirical data, why has it been so widely accepted it? We believe that the appeal of the essentialist position reflects a reaction against the rapid changes in family life that have taken place in the past three decades. Since the 1960's, family formation strategies have changed dramatically in Western, industrialized cultures (Blossfeld, 1995). The cultural norm of early and universal marriage has been reversed. Fertility rates have declined overall, and age at the birth of a first child has risen across all cohorts. More couples are choosing to live together outside the context of marriage, and a first pregnancy more frequently precedes, rather than follows marriage. Previously rare family types, e. g. single-mothers-by-choice, dual career, and gay/lesbian-parents are increasingly more common.

Industrialized cultures are in the process of changing from a context in which child development could flourish with fathers as the sole or primary provider, to a context in which two providers are now necessary in the vast majority of families. In a survey of $1,502 \mathrm{U}$. S. families, $48 \%$ of married women reported that they provided half or more of the family income (Families and Work Institute, 1995). Given this commitment to breadwinning, women can no longer shoulder the sole responsibility for raising children.

In this context of rapid change, the neoconservative position reflects a widespread societal anxiety about "Who will raise the children?" Mothers are no longer at home, and society has not embraced "other-than-mother" care. The U. S., in contrast to other western countries, has not yet developed a social policy agenda designed to help women and men integrate their work and family responsibilities. Thus, many people believe that a return to the traditional nuclear family structure with its gendered division of labor would be preferable to large numbers of neglected and unsupervised children.

In addition to an authentic concern about the welfare of children, we believe that the appeal of the "essential father" also reflects a backlash against the gay rights and feminist movements. In the past two decades, the employment of women has dramatically increased, while the employment of men has declined significantly (Engle \& Breaux, 1998). Many more women than in past historical periods can now choose to leave unsatisfactory marriages or to have children on their own, outside of the context of a traditional marriage. Two of three divorces are now initiated by women (Rice, 1994).

Just as the feminist movement created new opportunities for women, the gay rights movement has encouraged many more gay men and lesbians to live an openly homosexual lifestyle. Many gay men and women who would previously have entered into a heterosexual marriage in order to have children, now see a gay family structure as a viable alternative for raising children. Parallel to these changes, is the tendency emerging among heterosexual couples to live together and delay marriage until after a first pregnancy (Blossfeld, 1995). Thus, the distinctions between 


\section{AMERICAN PSYCHOLOGIST, VOLUME 54, NUMBER 6}

marital and cohabiting unions, and between marital and non-marital childbearing are losing their normative force.

These social changes require heterosexual men to relinquish certain aspects of power and privilege that they enjoyed in the context of the traditional nuclear family. Most men no longer have sole economic power over their families. Similarly, most men must accept some degree of responsibility for childcare and household tasks. The majority of heterosexual men no longer have full-time wives to buffer the stress of balancing work and family roles. Within this new context of power sharing and role sharing, heterosexual men have been moved from the center to the margins of many versions of family life. In our view, the societal debate about gender differences in parenting is, in part, a reaction to this loss of male power and privilege. We see the argument that fathers are essential as an attempt to reinstate male dominance by restoring the dominance of the traditional nuclear family with its contrasting masculine and feminine gender roles.

Family systems theory (Kerr \& Bowen, 1988) has proposed that natural systems (such as families and societies) fluctuate between periods of homeostasis and periods of disequilibrium. When change occurs, elements within the system react with a pressure to change the system back to its prior state of homeostasis. This cycle is called change and the change-back reaction. The current social context of multiple and diverse family structures, with their interchangeable parenting roles and more egalitarian distribution of power, challenges the dominant cultural ideology. From our perspective, the emphasis on the essential importance of fathers and heterosexual marriage represents a change-back reaction. It is an attempt to reassert the cultural hegemony of traditional values such as: heterocentrism; Judeo-Christian marriage; and male power and privilege.

\section{An Alternative Blueprint for Social Change}

We have argued that the neoconservative paradigm is based on an oversimplification of empirical research. Thus we believe that the social policy emanating from this perspective cannot ultimately be successful in encouraging responsible fathering. Pressuring men and women to enter into or maintain unsatisfactory marriages is unlikely to enhance paternal involvement. We will now present an alternative framework that we believe more accurately fits the data. Our framework has three main recommendations: reconstructing traditional masculinity ideology; restructuring societal institutions; and providing a comprehensive program of governmental subsidies to all families with children.

Because we believe that ideology defines both social policy and individual behavior, our first recommendation speaks to the necessity of reconstructing cultural ideology about gender roles. The neoconservative perspective also wants to reconnect fatherhood and masculinity. Blankenhorn (1995, p. 223) has stated that "being a real man [must come to mean] being a good father." However, within the essentialist framework, responsible fathering is inextricably intertwined with marriage. Our goal, in contrast, is to create an ideology that defines the father-child bond as independent of the father-mother relationship. 


\section{AMERICAN PSYCHOLOGIST, VOLUME 54, NUMBER 6}

If the father-child bond were accorded the same importance as the mother-child bond, then young boys would be socialized to assume equal responsibility for the care and nurturing of their children. A father's relationship with his children could then develop and remain independent of his relationship with the child's mother. This ideological shift would encourage the development of diverse models of responsible fatherhood. Roopnarine, Snell-White, \& Riegraf (1993) described a group of African Caribbean fathers living in a variety of relationship contexts, e. g. marital, common law, and "friending," who behaved responsibly to both biological and step-children. These data indicate that responsible fathering need not be dependent on a marital relationship.

We believe that this change in cultural gender ideology would be effective in maintaining a high level of paternal involvement for resident as well as nonresident fathers. Divorce and nonmarital childbirth would then be less likely to be characterized by father absence, since cultural norms would prescribe that never-married and divorced fathers remain actively involved with their children.

This ideological enhancement of the father-child bond is also necessary for restructuring societal institutions so that father involvement is encouraged, rather than inhibited. Maintaining the sacred status of the mother-child dyad continues the myth of separate, i. e. gendered, spheres of life. The cultural assumption of separate spheres links public/work/masculine and private/family/feminine. This cultural linking of family and feminine is reflected in the assumption that women, but not men, will decrease their involvement in paid work in order to balance the competing demands of work and family life.

Pleck (1993) found that men are reluctant to take advantage of family-supportive policies because they fear that they will be perceived as uncommitted to their job, or unmasculine. Until workplace norms acknowledge that men have equivalent responsibility for childcare, it is unlikely that most men will feel comfortable restructuring their commitment to work in a manner that allows more family involvement.

In the context of poor, ethnic minority families, it is often fathers, rather than mothers who have no resources to exchange. More than a decade ago, Wilson (1987) pointed out that institutionalized racism caused minority men to be marginalized, first from the labor market, and then from the family. Governmental policy must acknowledge the link between father absence and job absence. Men who can contribute substantially to family finances are more likely to get married and to assume financial responsibility for their children.

Our final recommendation relates to an overall governmental family policy. The U. S. cultural ideology of rugged individualism continues to assume that individual families can and should balance the stress of work and family without the benefits of large-scale government supports. The U. S. remains one of the few industrialized countries without a comprehensive family policy that provides: paid parental leave, governmentally financed day care, and economic subsidies for

all families with children. Without these benefits, the responsibility for childcare continues to fall largely on women. 


\section{AMERICAN PSYCHOLOGIST, VOLUME 54, NUMBER 6}

Because women continue to bear the bulk of the responsibility for the welfare of children, the goal of economic equality remains elusive. Providing families with governmental supports would not only alleviate many of the stresses of working families, it would also free women from the unequal burden of making major accommodations in their involvement in paid work. This shift would then decrease gender inequalities in the workplace, provide women with more resources to exchange, and thus contribute to higher paternal involvement.

How can these societal changes be achieved? Haas (1993) pointed to the high participation by women in politics as one of the social forces that has been significant in establishing progressive family policy in Sweden. Since the early 1970s, women have held one-third or more of the seats in parliament, compared to $12 \%$ in the 1996 U. S. Congress (The World Almanac, 1998). The example of Swedish politics suggests that until more women become active in government, many of the governmental supports needed to help families may not be forthcoming.

\section{Conclusion}

We have tried to illustrate how the essentialist position does not accurately reflect relevant empirical research. We have provided an alternative explanation of the research, and generated recommendations for social policy supports to mothers and fathers that we believe will more effectively achieve the goal of reconnecting fathers and children. We hope that this article will generate scholarly debate within the psychological community, and encourage a critical analysis of the essentialist paradigm.

\section{References}

Amato, P. R., Loomis, L. S., \& Booth, A. (1995). Parental divorce, marital conflict, and offspring well-being during early adulthood. Social Forces, 73, 895-915.

Archer, J. (1996). Sex differences in social behavior. Are the social role and evolutionary explanations compatible? American Psychologist, 51, 909-917.

Auerbach, C., \& Silverstein, L. (1997, November). Symposium Co-chairs. Is parenting gendered? A postmodern conversation. National Conference on Family Relations, Arlington, VA.

Auerbach, C., Silverstein, L. \& Zizi, M. (1997). The evolving structure of fatherhood: A qualitative study of Haitian American fathers. Journal of African American Men, 2, 59-85.

Biller, H. B. \& Kimpton, J. L. (1997). The father and the school-aged child. In M. E. Lamb (Ed.) The role of the father in child development. Third Edition (pp. 143-161). New York: John Wiley \& Sons, Inc.

Blankenhorn, D. (1995). Fatherless America: Confronting our most urgent social problem. New York: Basic Books.

Blossfeld, H-P. (Ed.) (1995). The New Role of Women. Boulder, CO: Westview. 


\section{AMERICAN PSYCHOLOGIST, VOLUME 54, NUMBER 6}

Booth, A. \& Crouter, A. C. (1998). Men in families. When do they get Involved? What difference does it make? Mahwah, NJ: Lawrence Erlbaum.

Bowlby, J. (1951). Maternal care and mental health. Geneva: World Health Organization.

Bowman, P. J. \& Forman, T. A. (1998). Instrumental and expressive family roles among African American fathers. In R. Taylor, J. Jackson, \& Chalters (Eds.), Family life in Black America (pp. 216-261). Newbury Park, CA: Sage.

Buss, D. M. (1995). Psychological sex differences. Origins through sexual selection. American Psychologist, 41,164-168.

Covenant Marriage Act. (1997). LSA-R.S. 9:272, et seq.

Daly, M., \& Wilson, M. (1985). Child abuse and other risks of not living with both parents. Ethology and Sociobiology, 6, 197-210.

Emery, R. E. \& Laumann-Billings, L. (1998). An overview of the nature, causes, and consequences of abusive family relationships. Toward differentiating maltreatment and violence. American Psychologist, 53, 121-135.

Engle, P. L., \& Breaux, C. (1998). Fathers' involvement with children: Perspectives from developing countries. Social Policy Report. Society for Research in Child Development, XII, $1-23$.

Erikson, R. J., \& Gecas, V. (1991). Social class and fatherhood. In F. W. Bozett \& S. M. H. Hanson (Eds.), Fatherhood and families in cultural context. Springer series: Focus on Men: Vol. 6 (pp. 114-137). New York: Springer.

Families and Work Institute. (1995). Women. The new providers. New York: Whirlpool Foundation Study.

Fischhoff, B. (1990). Psychology and public policy: Tool or toolmaker? American Psychologist, $45,647-653$.

Gould, S. J. (1997, July 12). Darwinian fundamentalists. The New York Review of Books, 10, 34-37.

Gowaty, P. A. (1997). Introduction: Darwinian feminists and feminist evolutionists. In P. A. Gowaty (Ed.) Feminism and evolutionary biology (pp. 1-18). New York: Chapman \& Hall.

Greif, G. L., \& DeMaris, A. (1990). Single fathers with custody. Families in Society: The Journal of Contemporary Human Services, 71, 259-266.

Haas, L. (1993). Nurturing fathers and working mothers: Changing gender roles in Sweden. In J. C. Hood (Ed.), Men, work, and the family (pp. 238-261). Newbury Park, CA: Sage. 


\section{AMERICAN PSYCHOLOGIST, VOLUME 54, NUMBER 6}

Haraway, D. (1989). Primate visions. New York: Routledge.

Harlow, C. W. (1991). Female victims of violent crime. Bureau of Justice Statistics, U. S. Department of Justice.

Haygood, W. (1997, November 30). Underground dads. The New York Times Magazine, Section 6. P. 156.

Hetherington, E. M., Bridges, M., \& Insabella, G. M. (1998). What matters? What does not? Five perspectives on the association between marital transitions and children's adjustment. American Psychologist, 53, 167-184.

Hrdy, S. B. (1997). Raising Darwin's consciousness: Female sexuality and the prehominid origins of patriarchy. Human Nature, 8, 1-49.

Kerr, M. \& Bowen, M. (1988). Family Evaluation. New York: W. W. Norton.

Lamb, M. E. (1987). The emergent American father. In M. Lamb (Ed.), The father's role: Cross-cultural perspectives (pp. 3-25). Hillsdale, NJ: Lawrence Erlbaum.

Lamb, M. E. (1997). Fathers and child development: An introductory overview and guide. In M. E. Lamb (Ed.) The role of the father in child development. Third Edition (pp. 1-18). New York: John Wiley \& Sons, Inc.

LaRossa, R. (Chair). (1997, November). Perspectives for encouraging father involvement. National Conference on Family Relations, Arlington, VA.

Lytton, H. \& Romney, D. M. (1991). Parents' differential socialization of boys and girls: A meta-analysis. Psychological Bulletin, 109, 267-296.

Malkin, C. M., \& Lamb, M.E. (1994). Child maltreatment: A test of sociobiological theory. Journal of Comparative Family Studies, 25, 121-134.

McLoyd, V. C. (1998). Socioeconomic disadvantage and child development. American Psychologist, 53, 185-204.

Nsamenang, B. A. (1992). Perceptions of parenting among the Nso of Cameroon. In B. S. Hewlett (Ed.), Father-child relations: Cultural and biosocial contexts (pp. 321-343). New York: Aldine de Gruyter.

Patterson, C. J. (1995). Lesbian mothers, gay fathers, and their children. In A. R. D'Augelli \& C. F. Patterson (Eds.), Lesbian, gay, and bisexual identities over the lifespan (pp. 262-290). New York: Oxford University Press.

Patterson, C. J., \& Chan, R. W. (1997). Gay fathers. In M. E. Lamb (Ed.) The role of the father in child development. Third Edition (pp. 245-260). New York: John Wiley \& Sons, Inc. 


\section{AMERICAN PSYCHOLOGIST, VOLUME 54, NUMBER 6}

Phares, V. (1996). Fathers and developmental psychopathology. New York: John Wiley \& Sons.

Pleck, J. H. (1993). Are "family supportive" employer policies relevant to men? In J. C. Hood (Ed.), Men, work, and family (pp. 217-237). Newbury Park, CA: Sage.

Pleck, J. H. (1995). The gender role strain paradigm: An update. In R. F. Levant \& W. S. Pollack (Eds.), A new psychology of men (pp. 11-32). New York: Basic Books.

Pleck, J. H. (1997). Paternal involvement: Levels sources, and consequences. In In M. E. Lamb (Ed.) The role of the father in child development. Third Edition (pp. 66-103). New York: John Wiley \& Sons, Inc.

Popenoe, D. (1996). Life without father. New York: Martin Pressler Press.

Pruett, K. D. (1989). The nurturing male: A longitudinal study of primary nurturing fathers. In S. H. Cath, A. Gurwitt, \& L. Gunsberg (Eds.), Fathers and their families (pp. 389-405). Hillsdale, NJ: Analytic Press.

Rice, J. K. (1994). Reconsidering research on divorce, family life cycle, and the meaning of family. Psychology of Women Quarterly, 18, 559-585.

Roopnarine, J., Snell-White, P., Riegraf, N. (1993). Men's roles in family and society: Dominica, Guyana, and Jamaica. UNICEF and UWI, Kingston, Jamaica.

Rutter, M. (1974). The qualities of mothering. Maternal deprivation reassessed. New York: Jason Aronson.

Samuelson, R. J. (1996, June 17). Why men need family values. Newsweek, 127, 43, 58-61.

Sedlak, A. J., \& Broadhurst, D. D. (1996). Third national incidence study of child abuse and neglect. National Center on Child Abuse and Neglect, U. S. Department of Health and Human Services.

Silverstein, L. B. (1996). Fathering is a feminist issue. Pychology of Women Quarterly, 20, 3-27.

Silverstein, L. B., Auerbach, C. F., Grieco, L., \& Dunkel, F. (in press). Do Promise Keepers dream of feminist sheep? Sex Roles.

Silverstein, L. B., \& Phares, V. (1996). Expanding the mother-child paradigm: an examination of dissertation research 1986-1993. Pychology of Women Quarterly, 20, 39-54.

Silverstein, L. \& Quartironi, B. (1996, Winter). Gay fathers. The Family Psychologist, 12, 23-24. 


\section{AMERICAN PSYCHOLOGIST, VOLUME 54, NUMBER 6}

Smuts, B. B. \& Gubernick, D. J. (1992). Male-infant relationships in nonhuman primates: Paternal investment or mating effort? In B. S. Hewlett (Ed.), Father-child relations: Cultural and biosocial contexts (pp. 1-31). New York: Aldine de Gruyter.

Sternberg, K. J. (1997). Fathers, the missing parents in research on family violence. In M. E. Lamb (Ed.) The role of the father in child development. Third Edition (pp. 284-309). New York: John Wiley \& Sons, Inc.

Stier, H., \& Tienda, M. (1993). Are men marginal to the family? Insights from Chicago's inner city. In J. C. Hood (Ed.), Men, work, and family (pp. 23-44). Newbury Park, CA: Sage.

Thornhill, R. \& Thornhill, N. W. (1992). The evolutionary psychology of men's coercive sexuality. Behavioral and Brain Sciences, 15, 363-375.

Trivers, R. L. (1972). Parental investment and sexual selection, in B. Campbell (Ed.), Sexual selection and the descent of man 1871-1971 (pp. 136-179). Chicago: Aldine.

U. S. Department of Justice. (1998). Violence by intimates: Analysis of data on crimes by current or former spouses, boyfriends, and girlfriends. Washington, D. C: Bureau of Justice Statistics.

Way, N., \& Stauber, H. (1996). Are "absent fathers" really absent? Urban adolescent girls speak out about their fathers. In B. J. R. Leadbeater \& N. Way (Eds.), Urban girls. Resisting stereotypes, creating identities (pp. 132-148). New York: New York University Press.

Weil, F. (1996). Divorced fathers: A qualitative study. Unpublished Psy.D. Research Project. Ferkauf Graduate School of Psychology, Yeshiva University, Bronx, NY.

Welfare Reform Act, 104 U. S. C. Stat. 2110 (1996).

Wetzstein, C. (1998, April 15). Congress urged to provide economic, social incentives to preserve family. The Washington Times.

Wilson, W. J. (1987). The truly disadvantaged: The inner city, the underclass, and public policy. Chicago: University of Chicago Press.

The World Almanac. (1998). Mahwah, NJ: World Almanac Books.

Zihlman, A. L. (1997). Women's bodies, women's lives: An evolutionary perspective. In M. E. Morbeck, A. Galloway, \& A. L. Zihlman (Eds.) The evolving female. A life history perspective (pp. 185-197). Princeton, N. J: Princeton University Press. 


\section{AMERICAN PSYCHOLOGIST, VOLUME 54, NUMBER 6}

\section{Author Note}

The authors want to thank Cheryl B. Travis for her support as action editor for this article. Correspondence should be sent to Louise B. Silverstein, Ph.D., 99 Clinton Street, Brooklyn, NY 11201, email: LBSREMSEN@AOL.COM. 